\title{
The influence of antagonist muscle electrical stimulation on maximal hip adduction force
}

\author{
Sota NaKanO $\left.{ }^{1,2}\right)^{*}$, Chikamune WadA ${ }^{2)}$ \\ 1) Department of Rehabilitation, Kyushu University of Nursing and Social Welfare: 888 Tominoo, \\ Tamana City, Kumamoto 865-0062, Japan \\ 2) Graduate School of Life Science and Systems Engineering, Kyushu Institute of Technology, Japan
}

\begin{abstract}
Purpose] The aim of this study was to determine whether electrical stimulation of the tensor fascia lata muscle decreases voluntary maximum resistance to passive abduction motion in participants without disease of the central nervous system. [Subjects] The participants were 16 healthy men. [Methods] The hip joint was moved from $10^{\circ}$ adduction to $0^{\circ}$ adduction with an angular velocity of $7 \%$ s. During the passive leg motion, the subject was asked to resist the motion with maximum force. Two experimental conditions were prepared: (1) electrical stimulation provided to the tensor fascia lata muscle during the passive motion; and (2) no electrical stimulation provided. [Results] The force was $10.2 \pm 3.5 \mathrm{kgf}$ with electrical stimulation and $12.2 \pm 3.8 \mathrm{kgf}$ without electrical stimulation. [Conclusion] The results suggested that the maximum hip adduction force decreased in participants because of electrical stimulation of the tensor fascia lata muscle.

Key words: Electrical stimulation, Fascia lata muscle, Maximal hip adduction force
\end{abstract}

(This article was submitted Aug. 25, 2015, and was accepted Oct. 14, 2015)

\section{INTRODUCTION}

In Japan, the number of patients who receive long-term care provided by the government has been increasing annually ${ }^{1)}$. Most of these patients are bedridden and often have limited range of motion (ROM) secondary to articular or muscular contractures $^{2}$. It is often difficult for nursing care workers to change adult diapers in these patients because of severely limited hip joint ROM. Moreover, a major reason for worsening joint contractures is long-term joint immobility ${ }^{3,4)}$. Therefore, to prevent continued severe deterioration, physiotherapists should provide passive ROM to the hip joint during rehabilitation ${ }^{5}$. However, worsening ROM has been encountered after providing passive ROM because of excessive muscle contractions during passive exercise. In these situations, therapists are unable to determine an optimum condition for passive exercise.

A previous study showed that the wrist contracture of a patient with hemiplegia caused by stroke was improved temporarily upon electrical stimulation of an antagonist muscle ${ }^{6}$. Furthermore, another study has shown that electrical stimulation of an antagonist muscle while stretching was effective in decreasing spasticity in patients with cerebral palsy ${ }^{7)}$. These studies suggest that electrical stimulation of spastic muscles is effective in decreasing resistance during passive ROM for patients with diseases of the central nervous system. Therefore, the purpose of the present study was to determine whether electrical stimulation of the tensor fascia lata muscle decreases resistance to passive abduction motion in the hip joint to increase ROM of bedridden patients. In contrast, bedridden elderly patients without diseases of the central nervous system often have excessive muscle contractions against passive exercise ${ }^{8)}$. To explain this briefly, excessive contraction of muscles may be produced by voluntary movement. Therefore, at first, this study investigated whether electrical stimulation of the tensor fascia lata muscle can decrease voluntary maximum resistance to passive abduction motion in participants without central nervous system disease.

\footnotetext{
*Corresponding author. Sota Nakano (E-mail: nakano@kyushu-ns.ac.jp)

(C)2016 The Society of Physical Therapy Science. Published by IPEC Inc.

This is an open-access article distributed under the terms of the Creative Commons Attribution Non-Commercial No Derivatives (by-nc-nd) License $<$ http://creativecommons.org/licenses/by-nc-nd/3.0/>.
} 


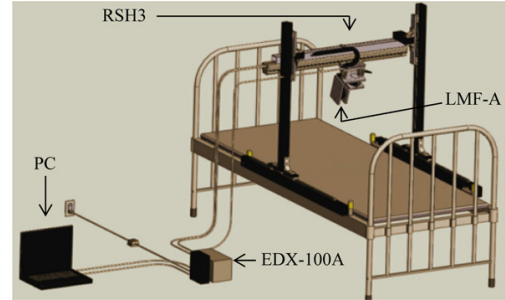

Fig. 1. Measurement system

The measurement system comprised a single-axis robot (RSH3), a force-measuring device (LMF-A), a universal recorder (EDX-100A), and the computer in which a robot controller was installed.

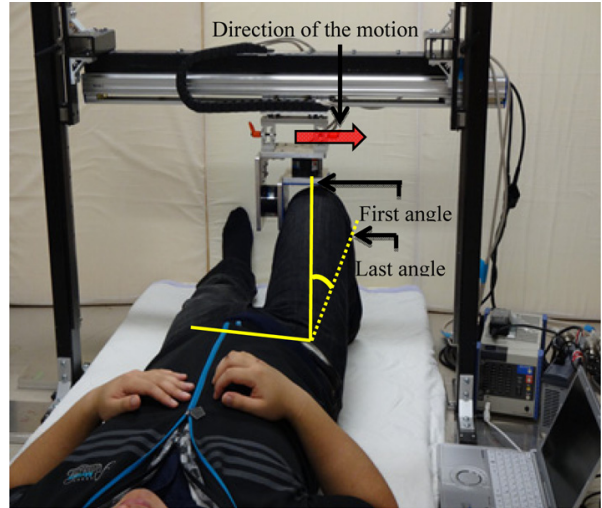

Fig. 2. Depiction of the measurement The hip joint was moved from $10^{\circ}$ adduction (first angle) to $0^{\circ}$ adduction (last angle) with an angular velocity of $7 \%$ s.

\section{SUBJECTS AND METHODS}

Figures 1 and 2 show the system used to measure the resistance force of the hip joint when the target leg was moved passively. The system comprised a single-axis robot, a force-measuring device, a robot controller, a universal recorder, and a computer. The RSH3 (Misumi Group Inc., $300 \mathrm{~mm} / \mathrm{s}, 339 \mathrm{~N}$ ) single-axis robot was used to move the leg laterally. This RSH3 was controlled by the RS-Manager. The LMF-A (Kyowa Electronic Instruments Co., Ltd., $1 \mathrm{kN}, 50 \mathrm{Nm}$ ) was used as the force-measuring device. This LMF-A could measure the 6-axis components of the force, and the force data were recorded on a computer at $100 \mathrm{~Hz}$, with the sampling performed by the EDX-100A (Kyowa Electronic Instruments Co., Ltd. $128 \mathrm{ch}$ ). The LMF-A was set on the RSH3, and the force applied to the leg was measured as it was moved passively by the RSH3. Our system could measure the passive resistive force of the hip adductors during passive hip abduction. The angular range and angular velocity of the passive motion were calculated as the main parameters.

The participants were 16 healthy men who volunteered to join this study. Participant characteristics are shown in Table 1. Participants were asked to lie down under the measurement system. Before initiating passive motion, the hip joint on the measurement side was set to the following parameters: $60^{\circ}$ of flexion and $10^{\circ}$ of adduction in the supine position. The value of $60^{\circ}$ was chosen tentatively because healthy people normally have $125^{\circ}$ of hip flexion, and the normal ROM of patients varies $^{9)}$. For the same reason, adduction was set to $10^{\circ}$. The center of the force-measuring device was placed at the medial epicondyle of the subject's femur. The hip joint was moved from $10^{\circ}$ adduction to $0^{\circ}$ adduction with an angular velocity of $7 \%$ s. Three angular velocities $(2 \% \mathrm{~s}, 7 \%$, and $12 \%$ s) were chosen for moving the hip joint passively based on the experience of the physiotherapist. However, because there were no significant differences among the three speeds in a preliminary experiment, the intermediate angular velocity $(7 \% \mathrm{~s})$ was adopted.

Considering wiping of the pubic region when changing the diaper, the hip joint was set at $0^{\circ}$ adduction so that the experimenter could put a hand near the pubic region. During passive leg motion, the subject was asked to resist the motion with maximum force, and the force data were recorded on a computer. Electrical stimulation was applied to the tensor fascia lata muscle using PROTECHNO PNF PRIME (Alpha Trinity Inc., $2.7 \mathrm{kHz}$, pulse $156 \mu \mathrm{s}$ ). In the preliminary experiment, the current value necessary to elicit tensor fascia lata muscle contraction was determined to be approximately $40 \mathrm{~mA}$. In this experiment, the current value was chosen so that contraction of the muscle was confirmed and the subject could endure stimulation. The electrical current ranged from 35 to $50 \mathrm{~mA}$ with an average of $40 \mathrm{~mA} \pm 3 \mathrm{~mA}$. During electrical stimulation, muscular contraction was confirmed using the muscle hardness meter PEK-1 (Imoto Machinery Co., Ltd.). In addition, the experimenter looked at the joint and confirmed that it did not move because of the muscle contraction. The experiment comprised two sessions. In the first session, passive motion was performed with electrical stimulation three times with 3-min rest intervals. The second session was performed more than a week later. In the second session, passive motion without electrical stimulation was performed three times with 3-min rest intervals. It was confirmed that the subjects had not performed any intense activities between the two sessions and had not experienced any myalgia before the experiment.

The mean value was used as the representative value for each session. Paired t-tests were used to compare the values of two sessions. All data were analyzed using standard statistics software (IBM SPSS Statistics ver. 19.0). P values of $<0.01$ were considered significant. This study was conducted in accordance with the ethical principles of the Declaration of Helsinki and was approved by the Ethics Committee of Kyushu University of Nursing and Social Welfare. 
Table 1. Participant characteristics

\begin{tabular}{lc}
\hline & Mean \pm SD \\
\hline Age (years) & $23.1 \pm 0.7$ \\
Height $(\mathrm{cm})$ & $170 \pm 6.0$ \\
Weight $(\mathrm{kg})$ & $64.3 \pm 10.0$ \\
\hline$(\mathrm{n}=16)$ &
\end{tabular}

Table 2. Comparison of the force between the conditions

\begin{tabular}{lc}
\hline Condition & FAD $(\mathrm{kgf}$, Mean \pm SD) \\
\hline Without ES & $10.2 \pm 3.5$ \\
With ES & $12.2 \pm 3.8$ \\
\hline
\end{tabular}

$(\mathrm{n}=16)$ FAD: force of the adduction direction ${ }^{*} \mathrm{p}<0.01$

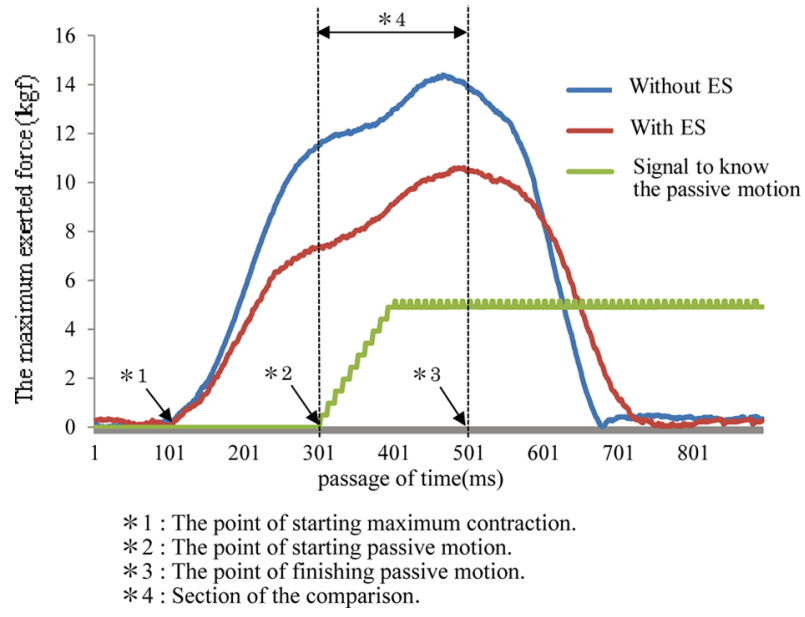

Fig. 3. Typical example of the maximum exerted force

\section{RESULTS}

Table 2 shows the comparison of the average of maximum exerted force (kgf) of hip adduction with and without electrical stimulation. The values with and without electrical stimulation were $10.2 \pm 3.5 \mathrm{kgf}$ and $12.2 \pm 3.8 \mathrm{kgf}$, respectively. A significant decrease in the resistance force was observed when electrical stimulation was applied. Figure 3 shows a typical example.

\section{DISCUSSION}

Our results showed that electrical stimulation of the tensor fascia lata muscle caused a decrease in maximum voluntary force applied in the direction of hip joint adduction. In the experiment, the participants produced force to the direction of hip adduction while the hip joint was passively moved in the direction of the abduction. Therefore, the movement caused an eccentric contraction of the hip joint adductor group. The factors affecting the force during an eccentric contraction include the angular velocity of the passive motion ${ }^{10,11)}$. Therefore, the influence of electrical stimulation was investigated in this experiment under a constant angular velocity. We hypothesized that the maximum force exerted may decrease for the following reasons: (1) the abductor muscle was electrically stimulated, thus generating abductor muscle tension and decreasing the adductor force; (2) reciprocal inhibition decreased the activity of the adductor muscle group because of activation of the antagonist abductor muscle. However, hypothesis (1) was not considered proven because the strength of electrical stimulation was relatively small. Muscle contraction was confirmed by a muscle hardness meter, but the joint motion was not confirmed. Therefore, the results of the experiment were attributed to hypothesis (2). Reciprocal inhibition has been proven using an $\mathrm{H}$ wave in healthy humans ${ }^{12,13)}$. In these experiments, the strength of the electrical stimulation was set near to the threshold of the $\mathrm{M}$ wave so that the appearance of the $\mathrm{H}$ wave was not disturbed ${ }^{14}$. In our experiment, tetanic contraction of the tensor fascia lata muscle was produced by electrical stimulation. Consequently, because the nerve fiber received stimulation greater than the threshold, reciprocal inhibition may have occurred at the spinal cord level. However, as the strength of stimulation was not lower than the threshold of the $\mathrm{M}$ wave, the possibility that other circuits in addition to disynaptic Ia reciprocal inhibition were functional could not be excluded ${ }^{15}$. A limitation of studies has been that the cause was not clarified because muscle activity was not measured ${ }^{16)}$. In conclusion, our study suggested that the maximum hip joint adduction force decreased because of electrical stimulation of the tensor fascia lata muscle. Future research will investigate the activity of the adductor group using an electrophysiological method.

\section{ACKNOWLEDGEMENT}

This research was financially supported by the JSPS KAKENHI (Grant Number 24650340).

\section{REFERENCES}

1) Ministry of Health: Labour and Welfare. Care insurance project status report. http://www.mhlw.go.jp/topics/kaigo/ toukei/joukyou.html\#link01 (Accessed May 19, 2015). 
2) Taketomi Y, Ichihashi N: Netakiriroujinn no kashikoushyuku no jittai. Jpn J Phys Ther, 1994, 28: 853 -856 (in Japanese).

3) Ono $\mathrm{T}$, Oki S, Umei N, et al.: Effect of an intermittent eight-hour joint fixation period on joint contractures in rats. $\mathrm{J}$ Phys Ther Sci, 2014, 26: 53-55. [Medline] [CrossRef]

4) Kondo Y, Nakano J, Sakamoto J, et al.: Effects of prolonged stretching and thermotherapy on muscle contracture of immobilized rat soleus muscle. J Phys Ther Sci, 2012, 24: 541-547. [CrossRef]

5) Ishikura H, Ono T, Oki S, et al.: Effect of stretch on improvement of muscular contractures in rats. J Phys Ther Sci, 2015, 27: 2821-2823. [Medline] [CrossRef]

6) Pandyan AD, Granat MH, Stott DJ: Effects of electrical stimulation on flexion contractures in the hemiplegic wrist. Clin Rehabil, 1997, 11: 123-130. [Medline] [CrossRef]

7) Khalili MA, Hajihassanie A: Electrical simulation in addition to passive stretch has a small effect on spasticity and contracture in children with cerebral palsy: a randomised within-participant controlled trial. Aust J Physiother, 2008, 54: 185-189. [Medline] [CrossRef]

8) Kawakami A, Kumagae T, Nishio Y, et al.: Comparison with the electromyogram of healthy control and contracture patient at rest and during passive motion. J Phys Ther Fukuoka, 2006, 19: 53-56 (in Japanese).

9) Yonemoto K, Ishigami S, Kondo T: Kansetukadouiki narabini sokuteihou. Jpn J Rehabil Med, 1995, 32: $207-217$ (in Japanese). [CrossRef]

10) Ikezoe K, Ichihasi N, Suzuki K, et al.: Hip abduction torque during concentric and eccentric contraction. Annual Reports of the College of Medical Technology. Kyoto Univ, 1994, 14: 49-52 (in Japanese).

11) Rodgers KL, Berger RA: Motor-unit involvement and tension during maximum, voluntary concentric, eccentric, and isometric contractions of the elbow flexors. Med Sci Sports, 1974, 6: 253-259. [Medline]

12) Day BL, Marsden CD, Obeso JA, et al.: Reciprocal inhibition between the muscles of the human forearm. J Physiol, 1984, 349: 519-534. [Medline] [CrossRef]

13) Mizuno Y, Tanaka R, Yanagisawa N: Reciprocal group I inhibition on triceps surae motoneurons in man. 1971, 34, 1010-1017.

14) deVries HA, Wiswell RA, Bulbulian R, et al.: Tranquilizer effect of exercise. Acute effects of moderate aerobic exercise on spinal reflex activation level. Am J Phys Med, 1981, 60: 57-66. [Medline]

15) Muraoka Y, Masakado Y, Tomita Y, et al.: Disynaptic Ia reciprocal inhibition in stroke patients before and after therapeutic electrical stimulation. Jpn J Rehabil Med, 2000, 37: 453-458 (in Japanese). [CrossRef]

16) Morita H: The evaluation of the spinal inhibitory system and its physiological significance. Clin Electroencephalogr, 2003, 45: 148-155 (in Japanese). 